\title{
Projected changes in population exposure to extreme heat in China under a RCP8.5 scenario
}

\author{
HUANG Dapeng ${ }^{1,2}$, ZHANG Lei ${ }^{3}$, GAO Ge ${ }^{1,2}$, SUN Shao ${ }^{1}$ \\ 1. National Climate Center, China Meteorological Administration, Beijing 100081, China \\ 2. Collaborative Innovation Center on Forecast and Evaluation of Meteorological Disasters, Nanjing University \\ of Information Science \& Technology, Nanjing 210044, China \\ 3. National Meteorological Center, China Meteorological Administration, Beijing 100081, China
}

\begin{abstract}
Overall population exposure is measured by multiplying the annual average number of extremely hot days by the number of people exposed to the resultant heat. Extreme heat is also subdivided into high temperature (HT) and extremely high temperature (EHT) in cases where daily maximum temperature exceeds $35^{\circ} \mathrm{C}$ and $40^{\circ} \mathrm{C}$, respectively. Chinese population exposure to HT and EHT over four periods in the future (i.e., 2021-2040, 2041-2060, 2060-2081 and 2081-2100) were projected at the grid cell level in this study using daily maximum temperature based on an ensemble mean of 21 global climate models under the RCP8.5 scenario and with a population projection based on the A2r socio-economic scenario. The relative importance of population and climate as drivers of population exposure was evaluated at different spatial scales including national and meteorological geographical divisions. Results show that, compared with population exposure seen during 1981-2010, the base period, exposure to $\mathrm{HT}$ in China is likely to increase by $1.3,2.0,3.6$, and 5.9 times, respectively, over the four periods, while concomitant exposure to EHT is likely to increase by $2.0,8.3,24.2$, and 82.7 times, respectively. Data show that population exposure to HT is likely to increase significantly in Jianghuai region, Southwest China and Jianghan region, in particular in North China, Huanghuai region, South China and Jiangnan region. Population exposure to EHT is also likely to increase significantly in Southwest China and Jianghan region, especially in North China, Huanghuai, Jiangnan, and Jianghuai regions. Results reveal that climate is the most important factor driving the level of population exposure in Huanghuai, Jianghuai, Jianghan, and Jiangnan regions, as well as in South and Southwest China, followed by the interactive effect between population and climate. Data show that the climatic factor is also most significant at the national level, followed by the interactive effect between population and climate. The rate of contribution of climate to national-level projected changes in exposure is likely to decrease gradually from ca. $70 \%$ to ca. $60 \%$, while the rate of contribution of concurrent changes in both population and climate is likely to increase gradually from ca. $20 \%$ to ca. $40 \%$ over the four future periods in this analysis.
\end{abstract}

Keywords: RCP8.5 scenario; population exposure; high temperature; extremely high temperature; driving forces

Received: 2018-01-09 Accepted: 2018-02-28

Foundation: National Natural Science Foundation of China, No.41101517; National Industry-specific Topics, No.GYHY201506051; National Natural Science Foundation of China, No.41701103

Author: Huang Dapeng (1978-), PhD and Associate Professor, specialized in natural hazard risk assessment, climate change impact assessment and application of remote sensing \& GIS. E-mail: dapenghuang@163.com 


\section{Introduction}

The Fifth Assessment Report of the United Nations Intergovernmental Panel on Climate Change (IPCC) noted that global average combined land and ocean surface temperature followed a linear trend between 1880 and 2012 and has increased by $0.85^{\circ} \mathrm{C}$ (IPCC, 2014a). Rising temperatures globally have increased the risk of heat-related deaths and illnesses; the risk of mortality and morbidity during periods of extreme heat, particularly for vulnerable urban populations and those working outdoors in urban or rural areas, has been identified as one of the key risks of climate change (IPCC, 2014b). Indeed, extreme heat events have been reported with increasing frequency all around the world; the summers of 2003 and 2010 were the warmest on record over approximately $25 \%$ of Europe (Barriopedro et al., 2011). In the earlier of these two years, much of Europe was affected by an extreme heatwave that caused more than 66,000 combined deaths in France, Germany, Italy, Portugal, and Spain (WMO, 2013), while the latter summer had a wider spatial extent and led to around 55,000 deaths in Russia (Barriopedro et al., 2011; Grumm, 2011). Data also show that heatwaves became a more regular occurrence globally between 2011 and 2015 (WMO, 2016); 5,758 heatwave-related illness cases were reported in China during the summer of 2013, for example ( $\mathrm{Gu}$ et al., 2016), while the 2015 heatwave in Pakistan was the worst in more than 30 years, and caused the deaths of more than 1200 people in Karachi alone (Cheema, 2015). The afternoon temperature reached $51.0^{\circ} \mathrm{C}$ in Phalodi in the northwest of India on May 19th, 2016, a new record for the highest observed maximum national temperature (the previous record was $50.6^{\circ} \mathrm{C}$, recorded in 1956) (van Oldenborgh et al., 2018), while on July 7th, 2017, the city of Phoenix in the USA experienced a new record maximum temperature $\left(118^{\circ} \mathrm{F}\right)$, the highest in 112 years (Johnson, 2017). It now seems inevitable that excess heat poses an increasing threat to human life, and that this risk will be greatly aggravated if greenhouse gases are not considerably reduced (Mora et al., 2017). This phenomenon has attracted the attention of both governments and the scientific community, as a key component of climate change research. A range of previous studies have primarily explored high temperature spatiotemporal characteristics (Ding et al., 2010; Ye et al., 2014; Li et al., 2015; Yang et al., 2015; Perkins-Kirkpatrick and Gibson, 2017) and associated atmospheric circulation (Peng et al., 2005; Sun et al., 2011; You et al., 2011; Trenberth and Fasullo, 2012; Wang et al., 2017), as well as climatic characteristics (Zhai and Pan, 2003; Luterbacher et al., 2004; Shi et al., 2008; Schoof et al., 2017), and the impacts of extreme heat (Liu et al., 2008; Deng et al., 2009; Tan et al., 2009; Gasparrini and Armstrong, 2011; Zhang et al., 2011; Blumberg, 2014; Chen et al., 2015; Zhao et al., 2015; Zuo et al., 2015; Xu et al., 2016; Benmarhnia et al., 2017). Risk assessments of extreme heat have also started to appear in the Chinese scientific literature, and a good deal of progress has been made nationally in this topic. Xie et al. (2015) recently presented a new conceptual framework that takes heat stress, social vulnerability, and population exposure into account in order to quantitatively assess county-level heat stress risk patterns across China. This risk assessment focused primarily on past high temperature events, however, and just represented heat stress and population exposure homogeneously at the county level. In earlier work, Yin et al. (2013) undertook a high temperature exposure analysis based on a number of extreme scenarios with return periods of 5 years, 10 years, 20 years, and 50 years, utilizing meteorological observation data, 
while He et al. (2010) assessed spatial patterns in extreme heat hazards across China within recent (between 1961 and 1990) and future (between 2011 and 2100) time periods on the basis of the IPCC SRES B2 emission scenario. More recently, Dong et al. (2014) projected future extreme heat risk based on 22 Coupled Model Intercomparison Project Phase 5 (CMIP5) model simulations and socioeconomic data to assess disaster vulnerability throughout China by integrating population density, gross domestic product, and cropland area percentage. One drawback of the Dong et al.'s study (2014) is that a detailed analysis of population exposure to high temperature was not performed. One aim of this study is therefore to project changes in population exposure to extreme heat under the RCP8.5 scenario across China at the level of individual grid cells based on NASA Earth Exchange Global Daily Downscaled Projections (NEX-GDDP) and the Greenhouse Gas Initiative (GGI) population scenario, in order to evaluate the relative importance of population and climate as drivers of national level population exposure as well as at the level of meteorological geographical divisions. The results of this study provide a clear scientific basis for the identification of hotspots of population exposure to extreme heat, and thus of targets for disaster risk prevention.

\section{Materials and methods}

\subsection{Data sources}

Daily maximum temperature data from 21 global climate models were downloaded from the NEX-GDDP dataset within the Climate Data Services provided by NASA. This NEX-GDDP dataset includes downscaled projections for RCP4.5 and RCP8.5 on the basis of 21 models and scenarios (Table 1) for which daily scenarios were produced and distributed via CMIP5. Thus, each of these climate projections includes daily maximum and minimum temperature as well as precipitation for the period between 1950 and 2100 . The spatial resolution of this dataset is 0.25 degrees (ca. $25 \mathrm{~km}$ by $25 \mathrm{~km}$ ). The RCP8.5 scenario was selected for analysis in this study and it represents high greenhouse gas emissions. Population scenario data were downloaded from the International Institute for Applied Systems Analysis GGI scenario database. This database encompasses three 'baseline' scenarios for different socioeconomic and technological developments, A2r, B1, and B2. The A2r scenario comprises a major numerical revision that reflects the most recent long-term demographic outlook with a corresponding lowering of future world population growth (Riahi et al., 2007). This population

Table 1 The 21 global climatic models included within NEX-GDDP

\begin{tabular}{lll}
\hline & \multicolumn{1}{c}{ Model name / Country } & \\
\hline ACCESS1-0 / Australia & CSIRO-MK3-6-0 / Australia & MIROC-ESM / Japan \\
BCC-CSM1-1 / China & GFDL-CM3 / USA & MIROC-ESM-CHEM / Japan \\
BNU-ESM / China & GFDL-ESM2G / USA & MIROC5 / Japan \\
CanESM2 / Canada & GFDL-ESM2M / USA & MPI-ESM-LR / Germany \\
CCSM4 / USA & INMCM4 / Russia & MPI-ESM-MR / Germany \\
CESM1-BGC / USA & IPSL-CM5A-LR / France & MRI-CGCM3 / Japan \\
CNRM-CM5 / France & IPSL-CM5A-MR / France & NorESM1-M / Norway \\
\hline
\end{tabular}


scenario was selected in this study because RCP8.5 climate scenario builds upon a socioeconomic and demographic background, resource assumptions and technological base of the A2r scenario (Riahi et al., 2011). The overall dataset has a resolution of 0.5 degrees (ca. 50 $\mathrm{km}$ by $50 \mathrm{~km}$ ) and a temporal resolution of 10 years. This A2r population scenario was interpolated to 0.25 degrees by averaging the original grid to match the spatial resolution of RCP8.5 scenario.

\subsection{Population exposure to extreme heat}

High temperature (HT) and extremely high temperature (EHT) are defined in this study based on Chinese climatic and environmental characteristics as cases when daily maximum temperature exceeds $35^{\circ} \mathrm{C}$ and $40^{\circ} \mathrm{C}$, respectively (Huang et al., 2011). The exposure definition proposed by Jones et al. (2015) states that population exposure to HT (or EHT) can be measured as annual mean high temperature days (or extremely high temperature days) multiplied by the number of people exposed to HT (or EHT). Annual mean high temperature days (or extremely high temperature days) are therefore calculated using the ensemble mean of 21 climate models in the RCP8.5 scenario. Population exposures for a base period between 1981 and 2010, as well as future periods between 2021 and 2040, 2041 and 2060, 2061 and 2080, and 2081 and 2100, are calculated in this study.

\subsection{Driving forces of changes in population exposure to extreme heat}

The population exposure can be influenced by the number of extreme heat days as well as the number of people. At the same time, changes in this variable can also result from climatic factor (i.e., changes in the number of extreme heat days while population levels remain constant), population factor (i.e., changes in population while the number of extreme heat days remains constant) and the interactive effect between the two (i.e., concurrent changes in population and climate). Change in population exposure is calculated as follows:

$$
(x+\Delta x) \cdot(y+\Delta y)-x \cdot y=x \cdot \Delta y+y \cdot \Delta x+\Delta x \cdot \Delta y
$$

where $x$ and $y$ are the number of extreme heat days and the population level, respectively; $x \cdot \Delta y$ is the population factor; $y \cdot \Delta x$ is the climatic factor; and $\Delta x \cdot \Delta y$ is to the interactive factor of the two.

The relative importance of these three factors was calculated using the equations presented below. The climatic factor contribution rate was calculated as:

$$
\frac{y \cdot \Delta x}{(x+\Delta x) \cdot(y+\Delta y)-x \cdot y} \times 100 \%
$$

The population factor contribution rate was calculated as:

$$
\frac{x \cdot \Delta y}{(x+\Delta x) \cdot(y+\Delta y)-x \cdot y} \times 100 \%
$$

The interactive contribution rate of climate and population was calculated as:

$$
\frac{\Delta x \cdot \Delta y}{(x+\Delta x) \cdot(y+\Delta y)-x \cdot y} \times 100 \%
$$




\section{Results}

\subsection{China's population exposure to extreme heat}

The data presented in Figure 1 show that future population exposure to HT and EHT across China is likely to increase significantly from the 2020s onwards. The results also show that within the base period of this study, between 1981 and 2010, population exposure to HT was 5.841 billion person-days. The trends reveal that this HT exposure is likely to increase to 13.433 billion person-days, 17.723 billion person-days, 26.787 billion person-days, and 40.249 billion person-days over the periods between 2021 and 2040, 2041 and 2060, 2061 and 2081, and 2081 and 2100, respectively; these represent 1.3-, 2.0-, 3.6-, and 5.9-time increases, respectively, relative to the base period. Similarly, population exposure to EHT during the base period was 0.133 billion person-days; the results suggest that this exposure is likely to increase to 0.397 billion person-days, 1.243 billion person-days, 3.361 billion person-days, and 11.165 billion person-days over the periods between 2021 and 2040, 2041 and 2060, 2061 and 2081, and 2081 and 2100, respectively; these represent 2.0-, 8.3-, 24.2-, and 82.7-time increases, respectively, compared to the base period. It is clear that population exposure to EHT will increase significantly over the latter part of the 21 st century. Particular attention will therefore be required to address the adverse health effects of EHT and, looking to the future, monitoring and warning services should be strengthened.

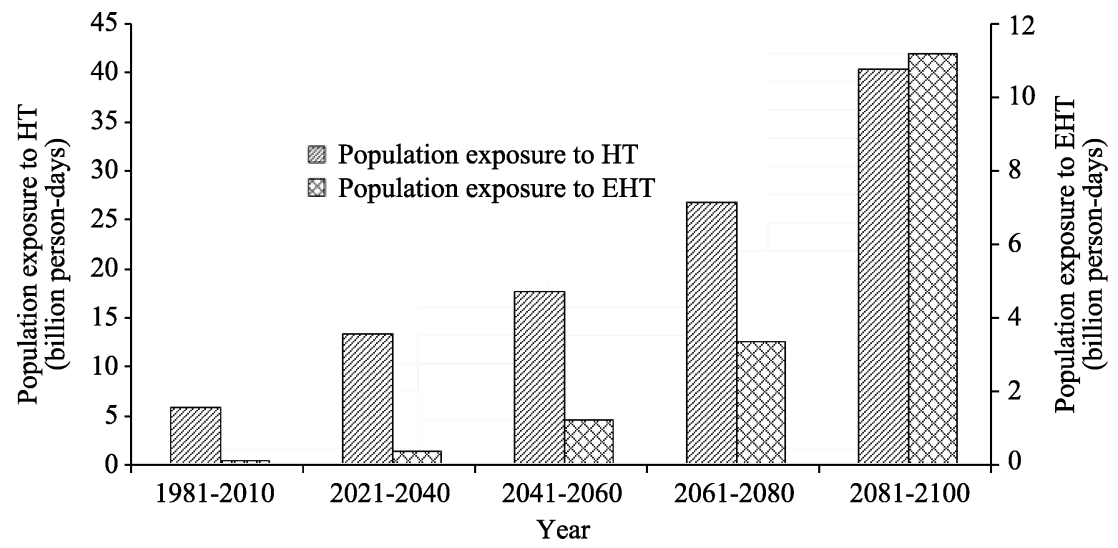

Figure 1 Plots showing Chinese population exposure to HT and EHT over the base period of this study, between 1981 and 2010, as well as future projected exposures under RCP8.5 climate scenario and A2r population scenario

\subsection{The spatial pattern of population exposure to HT}

Data show that during the base period of this study, between 1981 and 2010, population exposure to HT in southeastern Beijing, the central and eastern Tianjin, central and southern Hebei, western Shandong, northeastern Henan, northeastern Hubei, central and northern Jiangxi, eastern Hunan, and southwestern Chongqing ranged between four million person-days and ten million person-days, while population exposure to HT across most of China was less than one million person-days (Figure 2).

The results show that most parts of China will suffer HT exposure under the RCP8.5 scenario, with the exception of most of Gansu, Qinghai, Tibet, central and western Sichuan, and northern Yunnan. Into the future, relative to the base period between 1981 and 2010, the data 
show that population exposure to HT across most of China is likely to increase significantly between 2021 and 2041. Regions including southeastern Beijing, the central and eastern Tianjin, central and southern Hebei, western Shandong, northeastern Henan, parts of eastern Hubei and Hunan, and local areas of central Guangdong are likely to experience a large increase in exposure, ranging between ten million person-days and 20 million person-days (Figure $3 \mathrm{a}$ ). In addition, between 2041 and 2061, exposure across most of China, with the exception

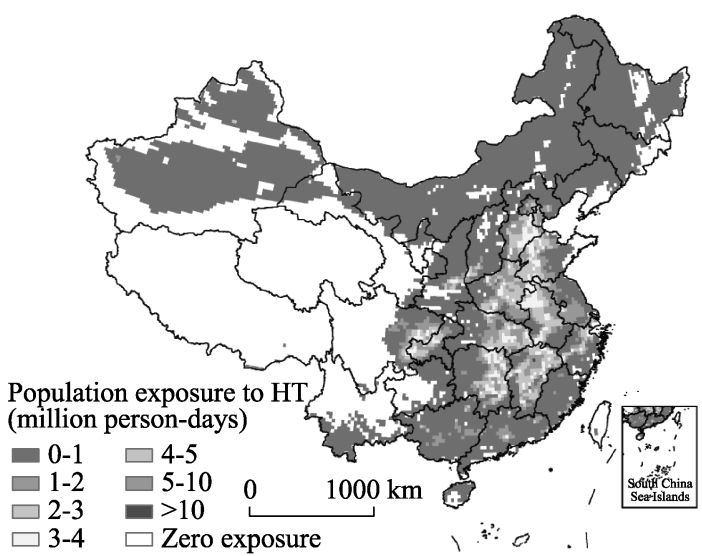

Figure 2 Map showing population exposure to HT over the base period of this study, between 1981 and 2010 of southeastern Xinjiang, is likely to continually increase, relative to the period between 2021 and 2040; indeed, exposure within southeastern Beijing, Tianjin, central and southern Hebei, western Shandong, northeastern Henan, northern Anhui, southern Jiangsu, parts of eastern Hubei and Hunan, and central Guangdong are projected to increase by between ten million person-days and 20 million person-days, while local areas of southeastern Beijing, Tianjin, Henan, Hubei, Shanghai, and Guangdong provinces are projected to see an increase in exposure exceeding 20 million person-days (Figure 3b). Further into the future, between 2061 and 2080, southeastern Beijing, Tianjin, central and southern Hebei, central and western Shandong, central and eastern Henan, northern Anhui, southern Jiangsu, central and southern Guangdong, southeastern Guangxi, and parts of eastern Hubei, central and eastern Hunan, the Sichuan Basin, and the Guanzhong region of Shaanxi are all likely to experience exposure increases of between ten million person-days and 20 million person-days compared to the period between 2041 and 2060. Over the same period, southeastern Beijing, central Tianjin, central and southern Hebei, western Shandong, northeastern Henan, central Guangdong, and local areas within Jiangsu, Shanghai, and Hubei are all likely to experience an increase in exposure exceeding 20 million person-days (Figure 3c). Finally, between 2081 and 2100, most of Beijing, Tianjin, central and southern Hebei, central and western Shandong, northeastern Henan, southern Jiangsu, central and southern Guangdong, and local areas within Shanghai, Zhejiang, Hubei, Hunan, and Guangxi as well as the Sichuan Basin and the Guanzhong region of Shaanxi are likely to experience increases in exposure exceeding 20 million person-days, compared to the period between 2061 and 2080 (Figure 3d).

The Handbook of Meteorological Geographical Divisions (NMC, 2006) subdivides China into 11 first-level meteorological geographical regions. These divisions are Northeast China (NE), Inner Mongolia (IM), North China (NC), the Huanghuai (HH), Jianghuai (JHuai), Jianghan (JHan), and Jiangnan (JN) regions, as well as South China (SC) and Southwest China (SW), the Qinghai-Tibet Plateau (QTP), Xinjiang (XJ), and the central-eastern part of Northwest China (CE of NWC). Data show that over the four future time periods considered in this study, the regions $\mathrm{NC}, \mathrm{HH}, \mathrm{SC}, \mathrm{JN}$, JHuai, SW, and JHan are all likely to experience significant increases in population exposure to HT (Figure 4). 

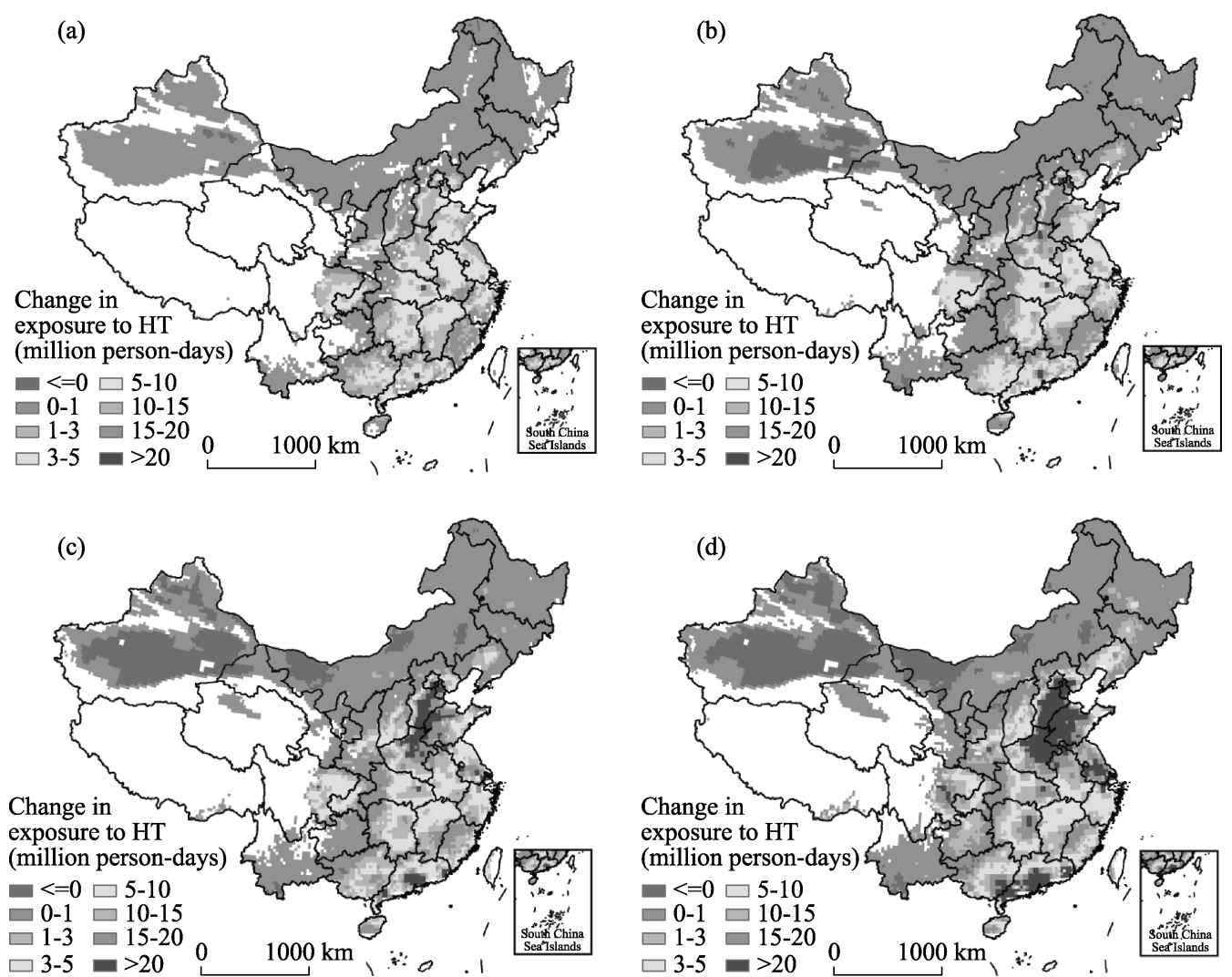

Figure 3 Maps showing projected changes in Chinese population exposure to HT into the future under RCP8.5 climate scenario and A2r population scenario. Maps showing (a) the exposure increment between 2021 and 2040 relative to the period between 1981 and 2010, (b) between 2041 and 2060 relative to the period between 2021 and 2040, (c) between 2061 and 2080 relative to the period between 2041 and 2060, and (d) between 2081 and 2100 relative to the period between 2061 and 2080

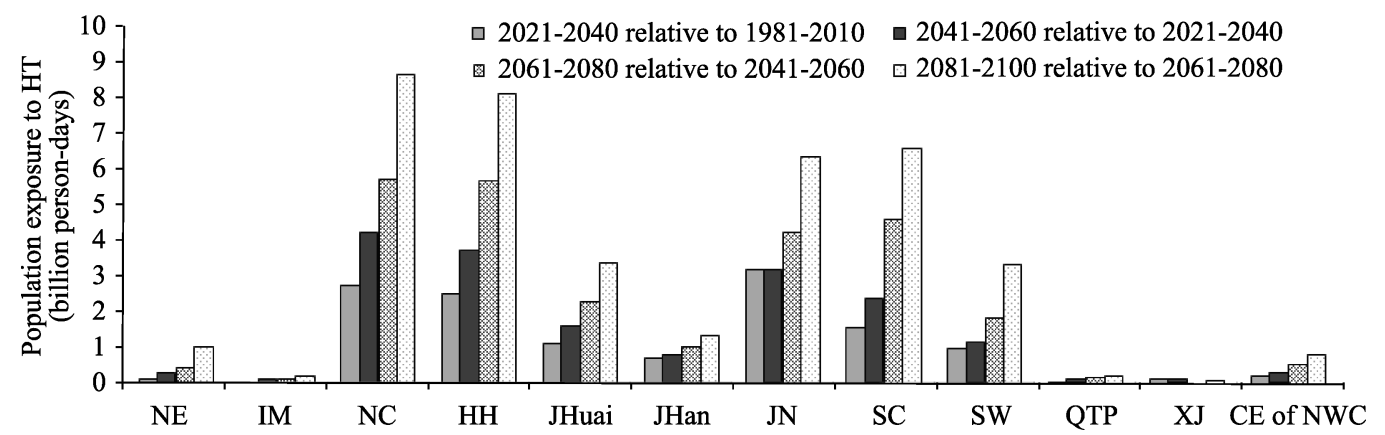

Figure 4 Projected changes in regional future population exposure to HT under the RCP8.5 climate scenario and $\mathrm{A} 2 \mathrm{r}$ population scenario within the different meteorological geographical divisions of China

Indeed, over the period between 2021 and 2040, population exposure in SC, JHuai, SW, and JHan is likely to increase by more than 0.7 billion person-days relative to the base period, while the $\mathrm{JN}, \mathrm{NC}$, and $\mathrm{HH}$ regions are likely to experience a larger increase in excess of 2.528 billion person-days. During the period between 2041 and 2060 relative to the period between 2021 and 2040, the SC, JHuai, SW, and JHan regions are likely to experience an 
increase of over 0.773 billion person-days of exposure, while the $\mathrm{NC}, \mathrm{HH}$, and JN regions are all likely to experience a larger increase, in excess of 3.177 billion person-days. Further into the future, the JHuai, SW, and JHan regions are all likely to experience an increase in exposure in excess of 1.029 billion person-days between 2061 and 2080 relative to the period between 2041 and 2060, while the SC, and JN regions will see a larger increase in excess of 4.246 billion person-days, and the largest increase, in excess of 5.682 billion person-days, will be seen in the NC and HH regions. Finally, data show that the JHuai and SW regions will all exhibit an increase in exposure of more than 3.336 billion person-days between 2081 and 2100 relative to the period between 2061 and 2080; within this, the SC, and $\mathrm{JN}$ regions are likely to exhibit a larger increase in excess of 6.396 billion person-days, while the largest exposure increase, in excess of 8.145 billion person-days, will be seen within the $\mathrm{NC}$ and $\mathrm{HH}$ regions.

\subsection{Spatial patterns in population exposure to EHT}

Data show that over the base period of this study, between 1981 and 2010, the population in parts of Xinjiang, Shaanxi, Shanxi, Inner Mongolia, Beijing, Tianjin, Hebei, Shandong, Henan, Anhui, Hubei, Jiangxi, Hunan and Chongqing all experienced EHT exposure at a level less than 0.1 million person-days. At the same time, population exposure to EHT in southeastern Beijing, central and southern Hebei, northeastern Henan, and in parts of central-northern Jiangxi ranged between 0.1 million person-days and 0.2 million person-days over the base time period (Figure 5).

The results of this study show that population exposure to EHT is likely to increase significantly under the RCP8.5 scenario and will affect more regions of China in the future. Predictions suggest that southeastern Beijing, central and eastern Tianjin, central and southern Hebei, northeastern Henan, eastern Hubei, central-northern Jiangxi, and eastern Hunan will all experience an increase in exposure between 2021 and 2040 relative to the base period at levels ranging between 0.6 million person-days and 1.2 million person-days (Figure 6a). Thus, data show that between 2041 and 2060, exposure in southeastern Beijing, most of Tianjin, central and southern Hebei, northwestern Shandong, northeastern Henan, eastern Hubei, central-northern Jiangxi, and northeastern Hunan is likely to increase by more than 1.2 million person-days when compared to the period between 2021 and 2040 (Figure $6 \mathrm{~b})$. Predictions also suggest that between 2061 and 2080, people living across most of central and eastern China will also experience EHT exposure, while those in eastern Beijing, Tianjin, central and southern Hebei, central and western Shandong, central and eastern Henan, central and northern Anhui, western and southern Jiangsu, northern Zhejiang, northern Jiangxi, eastern Hunan and Hubei, southwestern Chongqing, the southeastern part of the Sichuan Basin, the Guanzhong re-

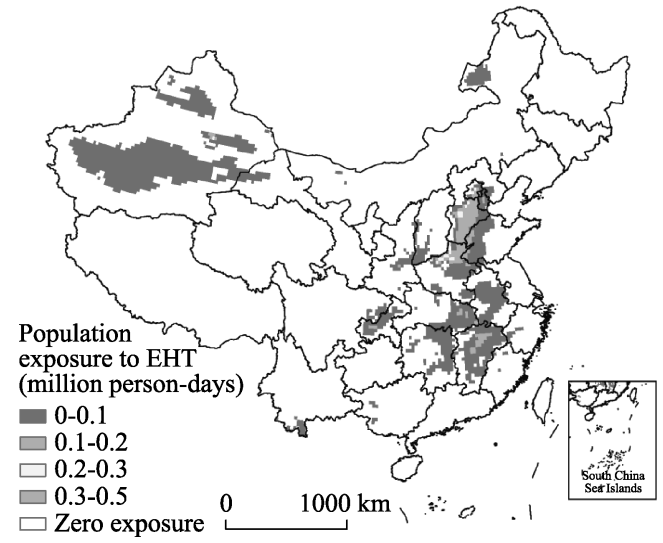

Figure 5 Map showing population exposure to EHT in China over the base period of this study, between 1981 and 2010 
gion of Shaanxi, and in southwestern Shanxi will all be subjected to an increase in excess of 1.2 million person-days between 2061 and 2080 relative to the period 2041-2060 (Figure 6c). Similarly, between 2081 and 2100, most of central and eastern China, western Chongqing, and the Sichuan Basin are likely to experience an increase in excess of 1.2 million person-days of exposure relative to the period between 2061 and 2080 (Figure 6d).
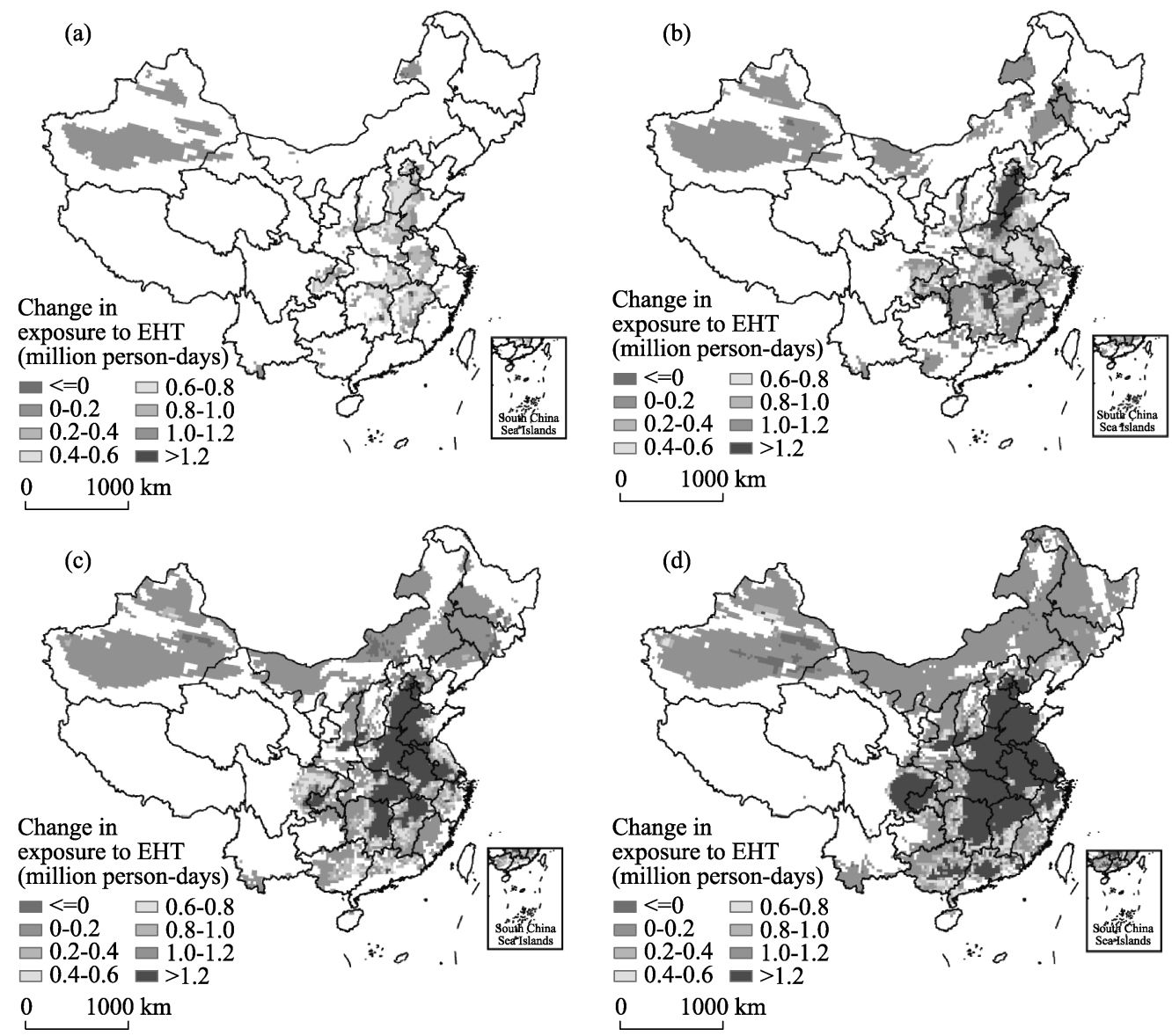

Figure 6 Maps showing projected changes in Chinese population exposure to EHT into the future under the RCP8.5 climate scenario and A2r population scenario. Maps show (a) the exposure increment between 2021 and 2040 relative to the period between 1981 and 2010, (b) between 2041 and 2060 relative to the period between 2021 and 2040, (c) between 2061 and 2080 relative to the period between 2041 and 2060, and (d) between 2081 and 2100 relative to the period between 2061 and 2080

Data show that the NC, HH, JN, JHuai, SW, and JHan regions will all experience significant increases in exposure to EHT (Figure 7). Indeed, relative to the base period, population exposure in JN, NC, JHuai, and $\mathrm{HH}$ is likely to increase by more than 0.039 billion person-days between 2021 and 2040. Over the period between 2041 and 2060, the NC, JN, HH, JHuai, JHan, and SW regions are likely to exhibit an increase in exposure in excess of 0.062 billion person-days relative to the period between 2021 and 2040. Specifically, the NC and $\mathrm{JN}$ regions are likely to experience a larger increase in excess of 0.316 billion person-days over this period. Further into the future, NC, HH, JN, JHuai, SW, JHan, CE of NWC, SC, 
and $\mathrm{XJ}$ will all experience an increase in exposure in excess of 0.034 billion person-days between 2061 and 2080 relative to the period between 2041 and 2060; over the period, the $\mathrm{NC}, \mathrm{HH}$, and JN regions are all likely to experience increases in exposure in excess of 0.688 billion person-days, while JHuai will experience an increase of more than 0.329 billion person-days. Data show that most regions of China, with the exception of NE, IM, QTP, and XJ, will experience an increase in exposure in excess of 0.182 billion person-days between 2081 and 2100 relative to the period between 2061 and 2080; increases in exposure within the NC and $\mathrm{HH}$ regions are likely to be in excess of 2.694 billion person-days while those within the JN, JHuai, SW, JHan, and SC regions will be in excess of 0.437 billion person-days.

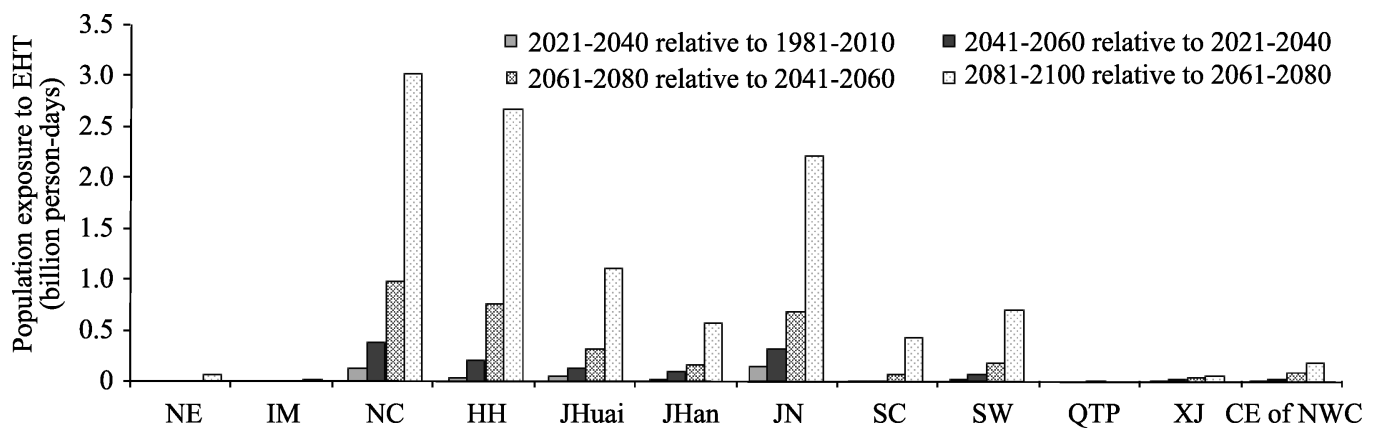

Figure 7 Projected changes in regional future population exposure to EHT under the RCP8.5 climate and A2r population scenarios within the different meteorological geographical divisions of China

\subsection{Driving forces of changes in future population exposure to HT and EHT}

The data presented in Table 2 show that the climatic factor is the most important driver of exposure at the national level, followed by the interactive effect between population and climate. Predictions suggest that the climate contribution rate to national-level projected changes in exposure will decrease gradually, from ca. $70 \%$ to ca. $60 \%$, while the contribution rate of concurrent changes in population and climate is likely to increase gradually over the four future time periods considered in this study, ranging between ca. $20 \%$ to ca. $40 \%$. In contrast, the influence of population on projected changes in exposure is predicted to be relatively small; the maximum contribution rates of population to changes in HT and EHT exposure are $13.1 \%$ and $7.7 \%$, respectively, between 2021 and 2041 relative to the period between 1981 and 2010 (Table 2).

The NC, HH, JHuai, JHan, JN, SC, and SW regions are predicted to be future hotspots that will experience significant changes in population exposure to HT and EHT. The contribution rates of climate, population, and the interaction between the two are listed in Table 3; the data show that changes in population exposure over the four future time periods will be driven mainly by climatic factor in the case of most hotspots (with the exception of NC), followed by the interaction between climate and population. Similarly, the population factor on exposure is likely to be relatively small across all hotspots, at a less than $9 \%$ contribution rate in most cases. The results show that the climatic factor will be absolutely dominant in terms of driving changes in population exposure to HT in the SW regions, at a contribution rate in excess of $90 \%$; this effect will also dominate changes in population exposure to EHT within the SW and SC regions (Table 3 ). 
Table 2 Analysis of the driving forces of changes in population exposure to HT and EHT across China (\%)

\begin{tabular}{|c|c|c|c|c|c|c|}
\hline \multirow[b]{2}{*}{$\begin{array}{c}\text { Change of population } \\
\text { exposure }\end{array}$} & \multicolumn{3}{|c|}{$\mathrm{HT}\left(\geqslant 35^{\circ} \mathrm{C}\right)$} & \multicolumn{3}{|c|}{$\mathrm{EHT}\left(\geqslant 40^{\circ} \mathrm{C}\right)$} \\
\hline & $\begin{array}{l}\text { Population } \\
\text { factor }\end{array}$ & $\begin{array}{l}\text { Climatic } \\
\text { factor }\end{array}$ & $\begin{array}{l}\text { Interactive } \\
\text { effect between } \\
\text { climate and } \\
\text { population }\end{array}$ & $\begin{array}{l}\text { Population } \\
\text { factor }\end{array}$ & $\begin{array}{l}\text { Climatic } \\
\text { factor }\end{array}$ & $\begin{array}{l}\text { Interactive } \\
\text { effect between } \\
\text { climate and } \\
\text { population }\end{array}$ \\
\hline $\begin{array}{l}\text { Between } 2021 \text { and } 2040 \\
\text { relative to } 1981-2010\end{array}$ & 13.1 & 67.6 & 19.4 & 7.7 & 68.9 & 23.4 \\
\hline $\begin{array}{l}\text { Between } 2041 \text { and } 2060 \\
\text { relative to } 2021-2040\end{array}$ & 2.9 & 67.6 & 29.5 & 0.9 & 67.1 & 32.1 \\
\hline $\begin{array}{l}\text { Between } 2061 \text { and } 2080 \\
\text { relative to } 2041-2060\end{array}$ & 1.5 & 66.3 & 32.2 & 0.3 & 65.4 & 34.4 \\
\hline $\begin{array}{l}\text { Between } 2081 \text { and } 2100 \\
\text { relative to } 2061-2080\end{array}$ & 1.8 & 58.4 & 39.9 & 0.1 & 59.9 & 40.0 \\
\hline
\end{tabular}

Table 3 Analysis of the driving forces of changes in population exposure to HT and EHT across the different meteorological geographical divisions of China (\%)

\begin{tabular}{|c|c|c|c|c|c|c|c|}
\hline \multirow[b]{2}{*}{$\begin{array}{l}\text { Change in } \\
\text { population } \\
\text { exposure }\end{array}$} & \multirow[b]{2}{*}{ Division } & \multicolumn{3}{|c|}{$\mathrm{HT}\left(\geqslant 35^{\circ} \mathrm{C}\right)$} & \multicolumn{3}{|c|}{$\mathrm{EHT}\left(\geqslant 40^{\circ} \mathrm{C}\right)$} \\
\hline & & $\begin{array}{l}\text { Population } \\
\text { factor }\end{array}$ & $\begin{array}{l}\text { Climatic } \\
\text { factor }\end{array}$ & $\begin{array}{l}\text { Interactive } \\
\text { effect between } \\
\text { climate and } \\
\text { population }\end{array}$ & $\begin{array}{l}\text { Population } \\
\text { factor }\end{array}$ & $\begin{array}{l}\text { Climatic } \\
\text { factor }\end{array}$ & $\begin{array}{l}\text { Interactive } \\
\text { effect between } \\
\text { climate and } \\
\text { population }\end{array}$ \\
\hline \multirow{7}{*}{$\begin{array}{l}\text { Between } 2021 \\
\text { and } 2040 \text { rela- } \\
\text { tive to between } \\
1981 \text { and } 2010\end{array}$} & $\mathrm{NC}$ & 30.1 & 40.0 & 29.9 & 19.0 & 45.6 & 35.5 \\
\hline & $\mathrm{HH}$ & 13.5 & 63.4 & 23.1 & 8.6 & 66.9 & 24.5 \\
\hline & JHuai & 11.1 & 68.3 & 20.6 & 3.4 & 75.7 & 20.9 \\
\hline & JHan & 9.0 & 72.1 & 18.9 & 2.4 & 77.8 & 19.8 \\
\hline & $\mathrm{JN}$ & 9.7 & 74.6 & 15.7 & 1.9 & 78.6 & 19.5 \\
\hline & $\mathrm{SC}$ & 3.9 & 78.9 & 17.2 & -12.7 & 152.6 & -39.9 \\
\hline & SW & 2.5 & 92.9 & 4.6 & 0.3 & 96.4 & 0.3 \\
\hline \multirow{7}{*}{$\begin{array}{l}\text { Between } 2041 \\
\text { and } 2060 \text { rela- } \\
\text { tive to between } \\
2021 \text { and } 2040\end{array}$} & $\mathrm{NC}$ & 8.7 & 39.7 & 51.7 & 2.6 & 43.5 & 53.9 \\
\hline & $\mathrm{HH}$ & 2.8 & 62.3 & 34.9 & 0.5 & 65.8 & 33.7 \\
\hline & JHuai & 2.0 & 67.9 & 30.1 & 0.3 & 71.7 & 28.0 \\
\hline & JHan & 1.7 & 73.0 & 25.3 & 0.1 & 74.0 & 25.9 \\
\hline & $\mathrm{JN}$ & 1.3 & 77.7 & 21.1 & 0.1 & 76.0 & 23.9 \\
\hline & $\mathrm{SC}$ & 0.3 & 76.2 & 23.5 & -0.4 & 125.1 & -24.7 \\
\hline & SW & -2.5 & 106.5 & -4.0 & -0.4 & 107.6 & -7.1 \\
\hline \multirow{7}{*}{$\begin{array}{l}\text { Between } 2061 \\
\text { and } 2080 \text { rela- } \\
\text { tive to between } \\
2041 \text { and } 2060\end{array}$} & $\mathrm{NC}$ & 4.7 & 36.6 & 58.7 & 0.7 & 40.0 & 59.2 \\
\hline & $\mathrm{HH}$ & 14.6 & 58.8 & 39.8 & 0.1 & 63.2 & 36.6 \\
\hline & JHuai & 1.1 & 64.3 & 34.6 & 0.1 & 67.6 & 32.3 \\
\hline & JHan & 1.1 & 71.3 & 27.6 & 0.0 & 71.2 & 28.8 \\
\hline & $\mathrm{JN}$ & 1.0 & 77.2 & 21.8 & 0.1 & 75.4 & 24.6 \\
\hline & $\mathrm{SC}$ & 0.2 & 71.7 & 28.1 & 0.0 & 92.8 & 7.2 \\
\hline & SW & -0.9 & 108.0 & -7.0 & -0.1 & 106.7 & -6.6 \\
\hline \multirow{7}{*}{$\begin{array}{l}\text { Between } 2081 \\
\text { and } 2100 \text { rela- } \\
\text { tive to between } \\
2061 \text { and } 2080\end{array}$} & $\mathrm{NC}$ & 3.6 & 31.8 & 64.6 & 0.3 & 35.3 & 64.4 \\
\hline & $\mathrm{HH}$ & 1.7 & 48.7 & 49.6 & 0.1 & 56.2 & 43.7 \\
\hline & JHuai & 1.5 & 54.3 & 44.2 & 0.1 & 61.3 & 38.6 \\
\hline & JHan & 2.0 & 61.2 & 36.9 & 0.0 & 65.5 & 34.5 \\
\hline & $\mathrm{JN}$ & 2.1 & 66.4 & 31.5 & 0.1 & 69.0 & 30.9 \\
\hline & $\mathrm{SC}$ & 0.4 & 62.1 & 37.6 & 0.0 & 80.9 & 19.1 \\
\hline & SW & 0.4 & 99.9 & -0.3 & 0.0 & 100.6 & -0.6 \\
\hline
\end{tabular}




\section{Discussion and conclusions}

Changes in population exposure to HT and EHT were projected across China in this study based on the most up-to-date global high-resolution climate models and the population projection data encapsulated in the A2r socio-economic scenario. This approach enabled a discussion of the factors influencing changes in population exposure over time.

The predictions presented in this study show that over the time periods between 2021 and 2040, 2041 and 2060, 2061 and 2080, and 2081 and 2100, national projected exposure to HT will increase by $1.3,2.0,3.6$, and 5.9 times, respectively, relative to the base period of this study, while projected exposure to EHT is likely to increase by 2.0, 8.3, 24.2, and 82.7 times, respectively. Future predictions suggest that HT conditions are likely to occur across most parts of China, with the exception of most of Gansu, Qinghai, Tibet, central and western Sichuan, and northern Yunnan, and the population exposure to HT will increase significantly from the period between 2021 and 2040 onwards. Over the period between 2081 and 2100, population exposure to HT is likely to increase significantly within Beijing, Tianjin, central and southern Hebei, central and western Shandong, northeastern Henan, southern Jiangsu, central and northern Anhui, eastern Hubei and Hunan, central and southern Guangdong, southeastern Guangxi, and the Sichuan Basin. Population exposure to EHT is likely to increase significantly in most parts of central and eastern China, western Chongqing, and the Sichuan Basin. In terms of meteorological geographical divisions, population exposure to $\mathrm{HT}$ is predicted to significantly increase in the $\mathrm{NC}, \mathrm{HH}, \mathrm{SC}, \mathrm{JN}$, JHuai, SW, and JHan regions over the four future time periods considered in this study, with those within the first four likely to be the most significant. Similarly, population exposure to EHT will increase significantly within the $\mathrm{NC}, \mathrm{HH}, \mathrm{JN}$, JHuai, SW, and JHan regions over the four future time periods, with increases in the first four again likely to be the most significant.

Population exposure to HT and EHT over the four future time periods considered in this study is likely to be mainly driven by climatic factor at the national level, followed by the interactive effect between climate and population. Data show that the climatic factor gradually decreases over the four future time periods, with the rate of contribution decreasing from $67.6 \%$ to $58.4 \%$ in the case of population exposure to HT and from $68.9 \%$ to $59.9 \%$ in the case of EHT. Similarly, the interactive effect between climate and population gradually increases with the contribution rate increasing from ca. $20.0 \%$ to ca. $40.0 \%$.

At the level of meteorological geographical divisions, changes in population exposure to HT and EHT in the NC region over the three periods (i.e., between 2041 and 2060 relative to 2021 and 2040, between 2061 and 2080 relative to 2041 and 2060, and between 2081 and 2100 relative to 2061 and 2080) are mainly driven by interactive effect between population and climate, followed by just the latter. In the HH, JHuai, JHan, JN, SC, and SW regions, data show that changes in population exposure are mainly driven by climatic factor, followed by interactive effects. Population factor on exposure is relatively small within each division going forward into future time periods; data show that the climatic factor absolutely dominates changes in population exposure to HT and EHT in the SW region, while the climatic factor absolutely dominates changes in population exposure to EHT in the SC region.

The results of this study show that there is likely to be an overall significant increase in population exposure to HT across much of central and eastern China in all future scenarios as well as a much more significant increase in EHT population exposure. Additional atten- 
tion should therefore be paid to monitoring and warning services in relation to future extreme heat within China.

The ensemble mean method that is commonly applied to project future climate change was used in this study to develop a series of extreme heat scenarios. The uncertainty inherent in multi-models requires further evaluation in the future. An analysis of population exposure to extreme heat at the grid scale is presented in this study in order to explore changes in population exposure as well as the impacts of population and climatic factor. A number of hotspots in population exposure changes are identified in this study, while the detailed findings provide guidance for extreme heat monitoring, warning, and risk prevention. Population exposure to extremely heat is an important component of heat stress risk assessment; the exploration of population exposure presented in this study therefore advances research on the risks associated with heat stress.

\section{Acknowledgements}

We thank Dr. Weile Wang (California State University-Monterey Bay) and Dr. Yingshuo Shen (NASA Goddard Space Flight Center) for their assistance in collecting the NEXGDDP dataset.

\section{References}

Barriopedro D, Fischer E M, Luterbacher J et al., 2011. The hot summer of 2010: Redrawing the temperature record map of Europe. Science, 332(6026): 220-224.

Benmarhnia T, Kihal-Talantikite W, Ragettli M S et al., 2017. Small-area spatiotemporal analysis of heatwave impacts on elderly mortality in Paris: A cluster analysis approach. Science of the Total Environment, 592: $288-294$.

Blumberg G, 2014. Assessing the potential impact of heat waves in cities: Implications for hazard preparation and planning. Procedia Economics and Finance, 18: 727-735.

Cheema A R, 2015. Pakistan: High-rise buildings worsened heatwave. Nature, 524(7563): 35.

Chen K, Bi J, Chen J et al., 2015. Influence of heat wave definitions to the added effect of heat waves on daily mortality in Nanjing, China. Science of the Total Environment, 506/507: 18-25.

Deng Zhenyong, Zhang Qiang, Xu Jinfang et al., 2009. Comparative studies of the harm characteristic of hot-dry wind and high temperature heatwaves. Advances in Earth Science, 24(8): 865-873. (in Chinese)

Ding T, Qian W H, Yan Z W, 2010. Changes in hot days and heatwaves in China during 1961-2007. International Journal of Climatology, 30(10): 1452-1462.

Dong Siyan, Xu Ying, Zhou Botao et al., 2014. Projected risk of extreme heat in China based on CMIP5 models. Advances in Climate Change Research, 10(5): 365-369. (in Chinese)

Gasparrini A, Armstrong B, 2011. The impact of heat waves on mortality. Epidemiology, 22(1): 68-73.

Grumm R H, 2011. The central European and Russian heat event of July-August 2010. Bulletin of the American Meteorological Society, 92(10): 1285-1296.

Gu S, Huang C, Bai L et al., 2016. Heat-related illness in China, summer of 2013. International Journal of Biometeorology, 60: 131-137.

He Shanfeng, Dai Erfu, Ge Quansheng et al., 2010. Pre-estimation of spatiotemporal pattern of extreme heat hazard in China. Journal of Natural Disasters, 19(2): 91-97. (in Chinese)

Huang Zhuo, Chen Hui, TianHua, 2011. Research on the heat wave index. Meteorological Monthly, 37(3): 345-351. (in Chinese)

IPCC, 2014a. Climate Change 2014: Synthesis Report. In: Contribution of Working Groups I, II and III to the Fifth Assessment Report of the Intergovernmental Panel on Climate Change. IPCC, Geneva, Switzerland.

IPCC, 2014b. Climate Change 2014: Impacts, Adaptation, and Vulnerability. Part A: Global and Sectoral Aspects. Contribution of Working Group II to the Fifth Assessment Report of the Intergovernmental Panel on Climate Change. Cambridge, United Kingdom and New York, NY, USA: Cambridge University Press.

Johnson W B, 2017. Phoenix breaks 112-year-old heat record. The Republic, azcentral.com. URL: http://www. azcentral.com/story/news/local/phoenix-weather/2017/07/07/phoenix-ties-112-year-old-heat-record/ $460738001 /$. 
Jones B, O’Neill B C, McDaniel L et al., 2015. Future population exposure to US heat extremes. Nature Climate Change, 5(7): 652-655.

Li Shuangshuang, Yang Saini, Zhang Donghai et al., 2015. Spatiotemporal variability of heat waves in Beijing-Tianjin-Hebei Region and influencing factors in recent 54 years. Journal of Applied Meteorological Science, 26(5): 545-554. (in Chinese)

Liu Jianjun, Zheng Youfei, Wu Rongjun, 2008. Impacts of heat waves disaster on human health and its research method. Journal of Natural Disasters, 17(1): 151-156. (in Chinese)

Luterbacher J, Dietrich D, Xoplaki E et al., 2004. European seasonal and annual temperature variability, trends, and extremes since 1500. Science, 2004, 303(5663): 1499-1503.

Mora C, Dousset B, Caldwell I R et al., 2017. Global risk of deadly heat. Nature Climate Change, 7(7): 501-506.

National Meteorological Center (NMC), 2006. Handbook of Meteorological Geographical Divisions in China. Beijing: China Meteorological Press. (in Chinese)

Peng Haiyan, Zhou Zengkui, Zhao Yongling et al., 2005. The analysis of abnormal high temperature in 2003 summer. Scientia Meteorologica Sinica, 25(4): 355-361. (in Chinese)

Perkins-Kirkpatrick S E, Gibson P B, 2017. Changes in regional heatwave characteristics as a function of increasing global temperature. Scientific Reports, 7: 12256. doi: 10.1038/s41598-017-12520-2.

Riahi K, Grübler A, Nakicenovic N, 2007. Scenarios of long-term socio-economic and environmental development under climate stabilization. Technological Forecasting and Social Change, 74(7): 887-935

Riahi K, Rao S, Krey V et al, 2011. RCP 8.5: A scenario of comparatively high greenhouse gas emissions. Climatic Change, 109(1): 33-57.

Schoof J T, Ford T W, Pryor S C et al., 2017. Recent changes in U.S. regional heat wave characteristics in observations and reanalyses. Journal of Applied Meteorology and Climatology, 56: 2621-2636.

Shi Jun, Ding Yihui, Cui Linli, 2008. Climatic characteristics and their changing law during summer high-temperature times in East China. Acta Geographica Sinica, 63(3): 237-246. (in Chinese)

Sun Jianqi, Wang Huijun, Yuan Wei, 2011. Decadal variability of the extreme hot event in China and its association with atmospheric circulation. Climatic and Environmental Research, 16(2): 199-208. (in Chinese)

Tan Jianguo, Lu Chen, Chen Zhenghong, 2009. Heat Waves and Human Health. Beijing: China Meteorological Press. (in Chinese)

Trenberth K E, Fasullo J T., 2012. Climate extremes and climate change: The Russian heat wave and other climate extremes of 2010. Journal of Geophysical Research: Atmospheres, 117(D17): 2399-2417.

van Oldenborgh G J, Philip S, Kew S et al., 2018. Extreme heat in India and anthropogenic climate change. Natural Hazards and Earth System Sciences, 18(1): 365-381.

Wang P, Tang J, Sun X et al., 2017. Heat waves in China: Definitions, leading patterns, and connections to large-scale atmospheric circulation and SSTs. Journal of Geophysical Research: Atmospheres, 122(20): 10679-10699.

World Meteorological Organization (WMO), 2013. The Global Climate 2001-2010, a Decade of Climate Extremes. Geneva, Switzerland: World Meteorological Organization.

World Meteorological Organization (WMO), 2016. The Global Climate in 2011-2015. Geneva, Switzerland: World Meteorological Organization.

Xie Pan, Wang Yanglin, Liu Yanxu et al., 2015. Incorporating social vulnerability to assess population health risk due to heat stress in China. Acta Geographica Sinica, 70(7): 1041-1051. (in Chinese)

Xu Z, Fitzgerald G, Guo Y et al., 2016. Impact of heatwave on mortality under different heatwave definitions: A systematic review and meta-analysis. Environment International, 89/90: 193-203.

Yang Honglong, Pan Jie, Zhang Lei, 2015. Characteristics of regional high temperature and heat wave events over China under SRES A2 scenario. Journal of Meteorology and Environment, 31(1): 51-59. (in Chinese)

Ye D X, Yin J F, Chen Z H et al., 2014. Spatial and temporal variations of heat waves in China from 1961-2010. Advances in Climate Change Research, 5(2): 66-73.

Yin Zhan'e, Yin Jie, Zhang Xiaowei, 2013. Multi-scenario-based hazard analysis of high temperature extremes experienced in China during 1951-2010. Journal of Geographical Sciences, 23(3): 436-446.

You Q, Kang S, Aguilar E et al., 2011. Changes in daily climate extremes in China and their connection to the large scale atmospheric circulation during 1961-2003. Climate Dynamics, 36(11/12): 2399-2417.

Zhai Panmao, Pan Xiaohua, 2003. Change in extreme temperature and precipitation over Northern China during the second half of the 20th century. Acta Geographica Sinica, 58(1): 1-10. (in Chinese)

Zhang Kehui, Li Zhengtao, Liu Jianfeng et al., 2011. Temporal-spatial feature analysis on the high-temperature and heatwaves in Hebei and its influence on industry and transportation. Geography and Geo-Information Science, 27(6): 90-95. (in Chinese)

Zhao Lin, Wang Changke, Li Xudong et al., 2015. Public perceptions of heat wave and its impacts and adaptation for different people groups in Hainan. Journal of Arid Meteorology, 33(2): 310-316. (in Chinese)

Zuo J, Pullen S, Palmer J et al., 2015. Impacts of heat waves and corresponding measures: A review. Journal of Cleaner Production, 92: 1-12. 